\title{
AS PALAVRAS Q̨UE CABEM NO TRÂNSITO DA VIDA: memórias de Ariel Dorfman ${ }^{1}$
}

\author{
Cláudio Pereira Elmir*
}

\section{Resumo}

O artigo analisa o livro Uma vida em trânsito. Memórias de um homem entre duas culturas (1998), do intelectual americano Ariel Dorfman. Com base na leitura de seu livro de memórias, procuramos verificar de que maneira o autor constrói, tendo por base a sua trajetória de vida e a de sua família, o bilinguismo que caracteriza este mesmo percurso. Pela constituição de suas múltiplas identidades, nem sempre excludentes, Dorfman traça, por meio das migrações que sempre estiveram em seu horizonte de vida, as razões da aproximação de um homem vinculado a projetos de esquerda na América Latina com as referências culturais norte-americanas.

Palavras-chave: “Uma vida em trânsito”. Chile. Estados Unidos. Migrações.

(...) lá estou eu no final dessa jornada na vida que também foi uma jornada paralela na morte, olhe para mim com as minhas duas línguas e minhas duas culturas, olhe para mim jurando retornar, olhe para mim excitado com o mundo à minha frente, olhe para mim enquanto esses dois mitos da existência humana me disputam, o mito que me prometeu que eu retornaria para sempre, o mito que murmurou que eu vagaria para sempre, lá estou eu, impossibilitado de adivinhar qual desses dois contém a verdade final de minha vida. (Ariel Dorfman)

É possível que alguém se perceba, ou que seja percebido, ao mesmo tempo como argentino, chileno e americano (norte-americano), além de judeu? E que também sustente vários nomes (pré-nomes), como Vladimiro (Vlady), Edward (Ed, Eddie), além de Ariel? E que, por essa série de duplicidades, veja-se simultaneamente como um homem do Sul e do Norte? É razoável supor que este mesmo homem nutra para si mesmo um discurso de

\footnotetext{
${ }^{1}$ Conferência apresentada no Seminário Internacional Migrações: mobilidade social e espacial; XIX Simpósio de Imigração e Colonização, ocorrido na UNISINOS, em São Leopoldo, de 15 a 17 de setembro de 2010. Foi mantida, no texto, a original estrutura oral de exposição.

* Doutor em História pela Universidade Federal do Rio Grande do Sul. Professor da Universidade do Vale do Rio dos Sinos. E-mail: elmir@unisinos.br
} 
identificação com projetos de esquerda e, simultaneamente, estabeleça um vínculo positivo com alguma coisa que possamos denominar de cultura americana (norte-americana)? Estes vários homens que cabem em um só não estariam nele, não fosse o conflito constitutivo que seus múltiplos engendram no correr da vida. Não que ser único possa representar qualquer garantia de quietude. Longe disso. A pessoa sobre a qual falo, se não soube desde sempre, aprendeu, até mesmo por dever de ofício, que os "planos" costumeiramente são muito desinteressantes. E na sua trajetória, para não falar na de sua família, ele se fez oblíquo, como as personagens complexas que encontramos nos melhores enredos produzidos pela ficção. Ariel Dorfman é um homem. Mas é, principalmente, para os propósitos desta análise, o nome que assina as memórias de alguém que muito cedo foi tocado pela língua - a espanhola e a inglesa - e fez dela a sua arma de luta e resistência; o instrumento de afirmação e de contestação no mundo. É desta história feita de tantas inflexões que quero agora falar. São as memórias de Ariel Dorfman, homem de muitos exílios, que gostaria de lhes contar. Se é difícil capturá-lo no espaço superficial da vida, talvez tenhamos que procurá-lo (e encontrá-lo) na escuta que sua narrativa nos proporciona. O meu convite a vocês é para que ouçamos juntos as palavras que se oferecem aos nossos ouvidos. Elas bem dizem as razões de ele ser tantos.

Começo me dando conta de uma deficiência. Ou seria apenas mais uma dobra a nos desafiar? As memórias de Ariel Dorfman, eu as li na tradução brasileira do livro. O livro que li, cuja história gostaria de compartilhar com vocês, leva o título Uma vida em trânsito: memórias de um homem entre duas culturas, e foi publicado pela editora Objetiva, do Rio de Janeiro, em 1998. A edição original, publicada no mesmo ano nos Estados Unidos em inglês, ganhou o título de Heading south, looking north - a bilingual journey. Em uma tradução livre, Dirigindo-se para o sul, olhando para o norte - uma jornada bilíngue. O que chamo de deficiente aqui não é propriamente a tradução, mas sim o fato de lermos a versão brasileira de um livro que precisou ser escrito em inglês para tratar do bilinguismo do autor. O português, neste caso, fala para os brasileiros sobre uma memória estranha a esta língua.

Fazendo parte do universo confessional, as memórias de Dorfman são dedicadas à Angélica, a mulher chilena do autor e mãe de seus dois filhos (Rodrigo e Joaquín). Ela, o amor de Dorfman - quase como o são o inglês e o espanhol - a quem ele diz: "Sin ti, no hubiera sobrevivido. Sem você, eu não teria sobrevivido” (DORFMAN, 1998, p. 5). Ela retorna várias outras vezes na narrativa para, ao final, ser reconhecida como aquela que o protegeu, a mulher que o manteve vivo e que abençoou a "aventura intelectual” na qual se constituiu o “doloroso” projeto-processo do livro (DORFMAN, 1998, p. 355-8). 
Mas afinal, vocês já devem estar se perguntando, sobre o que trata esta história? Que percurso ela cumpre? Quais são as memórias que Ariel Dorfman, seu autor, recupera e de que maneira ele as dispõe na narrativa de Uma vida em trânsito? Mais do que isto, talvez ao final possamos responder à questão sobre o interesse que este texto autobiográfico é capaz de suscitar para o leitor não interessado especificamente na vida de Ariel Dorfman. Correndo o risco de escapar à historicidade que nos delimita e a qual os historiadores frequentemente prezam, eu questionaria: onde reside o universal que torna esta história particular algo além de uma narrativa de si ou dos seus? Espero que no término desta exposição eu seja capaz de demonstrar, ainda que pelo exemplo de uma vida, traços de uma regularidade que atravessa a vida de tantos quantos se veem nas circunstâncias da mobilidade espacial, da migração, do exílio. Que a memória-história de Dorfman nos ajude, quem sabe, a enxergar o comum que possamos vislumbrar desde o próprio, sem perder de vista que a experiência de cada um é única; inclusive a da escrita do testemunho. ${ }^{2}$

Ariel Dorfman é um intelectual que se notabilizou internacionalmente por duas obras. Ele escreveu, junto com o sociólogo belga Armand Mattelart, Como ler o Pato Donald (1971), o seu livro mais conhecido, que vendeu "milhões de exemplares pelo mundo afora e [que] seria traduzido para mais de uma dezena de línguas” (DORFMAN, 1998, p. 322). Neste livro, encontra-se “(...) uma interpretação minuciosa de centenas de histórias em quadrinhos da Disney a partir de uma perspectiva do Terceiro Mundo” (DORFMAN, 1998, p. 322). Cerca de vinte anos depois, ele escreveria A morte e a donzela, uma peça que foi traduzida em mais de quarenta línguas e apresentada em mais de cem países. “A morte e a donzela é uma peça escrita em 1990 que traz uma situação paradigmática: o encontro entre uma torturada (e o marido) e seu torturador e a busca de justiça após a situação traumática vivida durante a ditadura” (ALVES, 2010, p. 113). Roman Polanski dirigiu a sua adaptação para o cinema

\footnotetext{
${ }^{2}$ Refletindo sobre a espacialização de suas histórias, especialmente aquelas que podem ser classificadas como textos de ficção, Dorfman aponta que o lugar aparente e declarado de sua realização não deve impedir que se estabeleçam vínculos de identificação, especialmente no trabalho de apropriação feito pelos leitores, dos lugares e das situações que eles conhecem de sua vivência: “(...) because I'm such a quintessential expatriate or exile that I'm writing from a perspective where I want this story to be about many people other than ourselves. I don't want this to be only about Latin America, only about Chile. I want it to go beyond our experience. I want the experience that I had in relation to Chile to be an experience which is valid for many people around the world, where readers around the world can read into the situation their own history so that my version of history, my decision that this is one moment to attend to, will not preclude other people reading into it their own moment, their own dreams, their own repression, their own falsification" (MC CLENNEN, s/d). Um exemplo disso é a peça "A morte e a donzela", em que, na descrição espaço-temporal da realização da história, diz-se: "O tempo é o presente e o lugar um país que é provavelmente o Chile, mas poderia ser qualquer país que elegeu um governo democrático logo após um longo período de ditadura” (DORFMAN, 1992, p. 9).
} 
alguns anos depois ${ }^{3}$. Dorfman vive hoje em Durham, na Carolina do Norte (EUA), atuando como escritor reconhecido por extensa e diversificada produção ${ }^{4}$ e como professor na área de literatura e estudos latino-americanos na Duke University. Não quero tratar destes textos famosos, e sim de Uma vida em trânsito, produção posterior do autor e que não obteve a repercussão dos livros anteriormente mencionados.

As memórias de Ariel Dorfman começam a ser concebidas em 1994. Sua redação é finalizada dois anos depois, no final de 1996. E a publicação do livro, como já referi anteriormente, deu-se em 1998, coincidindo com a prisão de Pinochet em Londres em outubro daquele ano, tema sobre o qual Dorfman dedicaria outro ensaio (DORFMAN, 2003). Em Uma vida em trânsito tem-se um texto fortemente marcado pela dicção pessoal, como são os livros de memórias. O objeto mais geral da narrativa é a vida do autor e as encruzilhadas que esta trajetória apresentou a ele em diferentes circunstâncias. Dorfman situa o cerne dos dilemas a ele postos na conjuntura do governo de Salvador Allende no Chile, entre os anos de 1970 e 1973, quando lá viveu e participou ativamente do projeto allendista de revolução. "Foram os melhores anos de minha vida” (DORFMAN, 1998, p. 317), diz ele. A posse de Allende, para Dorfman, aproximou-se de algo muito parecido a uma "experiência mística”, uma “epifania religiosa” (DORFMAN, 1998, p. 315). Nas suas palavras encantadas de hoje, que relembram o projeto ainda não abortado pelo golpe de 11 de setembro de 1973 :

(...) senti a vida se reanimar e acelerar, senti a vertigem daqueles raros grandes momentos na vida em que se sabe que tudo é possível, que qualquer coisa é possível. Senti como se eu fosse o primeiro homem da Terra e esse fosse o primeiro dia da História, e o mundo estivesse para começar em toda a sua beleza, e tudo que era preciso para dar à luz essa beleza que estava ao nosso alcance era ousar inventá-la, ousar dar-lhe um nome, e acreditei por um momento que podia me fundir no pueblo, acreditei que a sua história e a minha história podiam ser contadas simultaneamente, acreditei que chegaria o tempo em que nenhuma distância nos separaria, quando as nossas histórias seriam as mesmas histórias (DORFMAN, 1998, p. 315).

Em seguida, o autor reconhece que "havia estipulado uma meta impossível, utópica" (DORFMAN, 1998, p. 315). A sua história de vida, ele bem o sabia, estava muito distante de

\footnotetext{
${ }^{3}$ Um dos índices da importância do texto de Dorfman pode ser avaliado pela "disputa” havida entre seis ou sete diretores de cinema que pretendiam fazer o filme. Dorfman foi quem escolheu Polanski (cf. POSTEL, 1998).

${ }^{4}$ A produção intelectual de Dorfman alcança variadas formas literárias: ensaio, poesia, romance, teatro, memória, narrativa de viagem. A diversidade e variabilidade de gêneros são explicadas pelo autor por meio de sua própria trajetória de vida, sempre marcada pela experiência da mobilidade (espacial e linguística): "I think the genre decides for me - which sounds like a way of avoiding the question unless I explain first that this chameleon-like border crossing, this shifting of genre identities is, I realize, parallel to, or anticipates, or recollects my own life. I'm probably fluctuating across genres perhaps because my identity itself is always in flux" (MC CLENNEN, s/d).
} 
uma comunhão com o povo chileno. Dorfman queria fazer parte desta comunidade, identificar-se com "os de baixo", integrar-se às classes populares desta coletividade e construir com elas a superação de sua situação de miséria, de escassez. Muitos anos antes, quando ainda era uma criança, as condições de vida do menino Dorfman e seu encontro com a pobreza extrema de outras crianças que generosamente trouxe para casa para alimentar prenunciariam a opção pelos mais necessitados. Mas apontavam, ao mesmo tempo, para o abismo que separava o filho do diplomata da triste realidade das ruas de Santiago.

Falar um pouco sobre a família de origem de Ariel Dorfman ajuda a compreender, pelo menos em parte, os trânsitos da vida pelos quais ele passou. Mas antes disto, gostaria de expor, em breves palavras, como se estrutura a narrativa de Uma vida em trânsito. Que ordem organiza a narrativa; que divisão formal o autor operou de suas lembranças; em quais partes a sua vida foi distribuída na superfície do texto. Afinal, contar uma história por escrito, a sua própria história e a de sua família, é também orientar a leitura daqueles que irão conhecê-la. Daí que eu pergunto: como Ariel Dorfman deu-se a conhecer na história de si que ele mesmo inventou?

O livro de memórias de Dorfman foi dividido em duas grandes partes: a "Parte Um Norte e Sul” e a "Parte Dois - Sul e Norte", em um total de 16 capítulos; sem contar o “Prefácio a título de dedicatória”, o “Epílogo” e os “Agradecimentos”, sendo que o primeiro e o último cumprem a função de paratextos, constituindo narrativas paralelas explicativas da narrativa principal. O mais importante a ser dito sobre a divisão da matéria de sua exposição, no entanto, reside na intercalação que os capítulos desdobram entre o tempo diacrônico da vida do autor, desde antes de seu nascimento, quando a sua família emigrou da Europa para a América Latina, especificamente para a Argentina, e o tempo relativamente sincrônico da vida do autor localizado no ano de $1973^{5}$, até o ponto em que os tempos se encontram, no final da narrativa. Aos capítulos que remetem ao tempo diacrônico acompanha, quase sempre, a referência à “descoberta da vida e da língua”, ao passo que aos capítulos que tocam ao tempo sincrônico temos a “descoberta da morte”, expressa no título.

\footnotetext{
${ }^{5}$ O ano de 1973 é paradigmático no arranjo textual da memória e decisivo na vida do autor, conforme palavras de Dorfman em entrevista concedida por ocasião do lançamento de Uma vida em trânsito: "It was the moment in my life when everything changed, the moment of conception of the person I now am, how I became this person who's bilingual, who's multicultural, who's hybrid. I now have the perspective of twenty-five years of looking back on that. Why am I in exile? Why am I far away? Why do I speak English when I swore I wouldn't? It all has to do with the fact of the coup, and the fact that I was spared. Life pardoned me. History pardoned me. Violence passed me by. Death decided not to take me, I should have been at La Moneda Palace with Allende; I had become a collaborator of one of his chiefs of staff. My life has consisted of a series of encounters with death and is fundamentally about how I've escaped death. But in escaping death, I also had to escape my country. So I went into exile and became the person I now am" (POSTEL, 1998).
} 
O primeiro capítulo (“Capítulo que trata da descoberta precoce da morte”) inicia com a seguinte frase, a primeira frase do livro: "Eu não devia estar aqui para contar esta história” (DORFMAN, 1998, p. 13). O tom solene, dramático, sério, reconhecido pelo próprio autor (MC CLENNEN, s/d), iria conduzir todo o texto e não apenas seu princípio. Especialmente porque neste começo podemos entrever um sentimento de culpa por ele ter sobrevivido, por não ter sido um afogado, como tantos outros o foram desde o momento em que o general Augusto Pinochet e as forças armadas chilenas destituíram o presidente Allende e tomaram o poder. Os motivos que justificam a declaração de Dorfman (repito, "Eu não devia estar aqui para contar esta história”), ele mesmo oferece na sequência de seu raciocínio: “A razão é simples: há um dia em meu passado, um dia há muitos anos, em Santiago, no Chile, em que

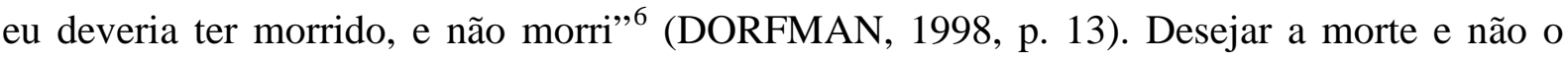
morrer (DORFMAN, 1998, p.15), fundava projeto que podia frequentar o pensamento de um jovem e idealista homem de 31 anos de idade, que via esfacelar diante dos seus olhos o plano maior de um governo popular e socialista que ele, e muitos outros, tanto acalentaram nos anos anteriores. Neste momento, Dorfman foi encarado pelo exílio (DORFMAN, 1998, p. 21), a besta-fera que o levou de volta para o Norte. Os (im)prováveis 17 anos de governo Pinochet contribuiriam para tornar este tempo definitivo, e o lento retorno da ordem institucional, desde o final da década de $1980^{7}$, faria deste exilado chileno um expatriado nos Estados Unidos. Hoje, um ilustre expatriado.

Mas quem era este exilado chileno nascido na Argentina? Que percurso ele e sua família de imigrantes cumpriram até este desfecho? Quantos exílios são capazes de caber em uma só vida? Quantas viagens tornam um homem aquilo que ele é? Quantas travessias cruzam os pontos cardeais e estabelecem novos portos de onde se sai e para onde se chega? Quanto daquilo que fazemos e dos lugares por onde passamos, ao longo da vida, pode ser atribuído às escolhas e aos destinos que nossos pais ou nossos avós reservaram para eles? É possível encontrar o próprio naquilo que é do outro? As memórias vicárias ainda assim podem ser nossas memórias? Será que todo bebê é apenas “(...) um bloco de notas no qual qualquer estranho poderia rabiscar uma assinatura”? (DORFMAN, 1998, p. 24). Estas são

\footnotetext{
${ }^{6}$ Na ocasião do golpe, Dorfman trabalhava como conselheiro cultural e de mídia, junto ao chefe do Estado-maior de Allende. Ele deveria cumprir um plantão no Palácio Presidencial na noite de 10 de setembro, mas dias antes pediu para trocar esse dia com um colega, o que o retirou do olho do furacão e o fez pensar, posteriormente, que "o acaso está brincando conosco" (DORFMAN, 1998, p. 19).

${ }^{7}$ Sobre o processo de transição da ditadura para um regime democrático no Chile são eventos significativos e emblemáticos: o plebiscito de 1988, que decide pela rejeição da permanência de Pinochet no poder; a reforma da Constituição e as eleições presidenciais de 1989, a qual devolve o poder a um presidente civil; a criação da Comissão Nacional de Verdade e Reconciliação, em 1990; o pedido de perdão oficial e reparações, em 1991, e a primeira condenação em 2002 (cf. COMPARATO, 2009).
} 
algumas das questões que me ocorre formular ao ler Uma vida em trânsito. Questões para as quais, menos que respostas, tenho apenas alguns indícios que a própria história familiar de Dorfman propõe, desde o seu particular ponto de vista.

Ariel Dorfman nasceu em 1942 na cidade de Buenos Aires. Seus pais vieram da Europa oriental, no início do século XX, filhos de judeus emigrados para a Argentina. Sobre a origem de sua mãe, ele afirma o seguinte:

Fanny Zelicovich Vaisman nasceu em 1909, em Kishinev. Seu lugar de nascimento, assim como a sua vida, sofreu as flutuações arbitrárias da História: naquela época, Kishinev pertencia à grande Rússia, mas, a partir de 1918, foi incorporada à Romênia, e, em 1940, à União Soviética - para se tornar, depois da desintegração desse país, a capital da república da Moldávia. Se minha mãe tivesse ficado lá, poderia ter trocado de nacionalidade quatro vezes, sem sair da rua em que vira a primeira luz deste mundo. Se bem que se tivesse ficado, provavelmente não teria vivido o bastante para fazer todas essas mudanças de cidadania (DORFMAN, 1998, p. 27).

Sobre a família do pai, Dorfman diz:

Adolfo nasceu em Odessa em 1907, então Ucrânia, depois Rússia, de uma família judia rica que estava na região havia pelo menos um século, provavelmente mais tempo. Além do russo, seu pai David Dorfman falava inglês e francês fluentemente, assim como sua mãe Raissa Libovich, que também era versada em alemão, depois de três anos de estudo em Viena. Todas essas línguas, mas não o iídiche: se consideravam assimilados, cosmopolitas, definitivamente europeus (DORFMAN, 1998, p. 31-2).

As razões pelas quais os avós de Ariel Dorfman resolveram sair do lugar onde moravam e migrar para a América com os filhos ${ }^{8}$ não eram as mesmas. Enquanto a família de seu pai deixa a Europa em função da falência de uma fábrica de sabão, fugindo para o exterior para escapar dos credores, a família de sua mãe vem para o sul da América porque estava sofrendo perseguição. $\mathrm{O}$ avô materno da mãe de Dorfman fora assassinado em um pogrom em 1903. É significativo que nas memórias do autor "ser judeu” não constitui uma centralidade, um traço distintivo relevante, embora a experiência do constante expatriamento possa ser associada a esta identificação.

Proveniente de família abastada e com pais poliglotas (David Dorfman e Raissa Libovich), Adolfo, pai de Ariel, construiu uma formação intelectual que o distinguiu, havendo

\footnotetext{
${ }^{8}$ A mãe de Ariel Dorfman, Fanny Zelicovich Vaisman, vem para a Argentina com três meses de idade, em 1909. Já o seu pai, Adolfo Dorfman, tinha três anos de idade quando foi para aquele país. Adolfo Dorfman, em 1914, volta para a Rússia com a mãe, lá vivendo com ela até o final de 1920, quando retornam para a Argentina.
} 
escrito livros, artigos e ensaios ao longo desta trajetória e tornado-se professor na Universidade de La Plata. Com tendências ideológicas esquerdistas e simpatizante ao regime socialista da União Soviética, Adolfo filia-se ao Partido Comunista em 1930, militando nele durante toda aquela década. O seu filocomunismo fez nomear o filho com o nome de Vladimiro. Uma homenagem ao líder da revolução na Rússia. De certa forma, uma responsabilidade atribuída ao futuro do menino. Uma guinada à direita na política argentina, em 1943, complica a situação da família e leva a que Adolfo fuja para os Estados Unidos no final daquele ano. Não tivesse o nascimento de Ariel Dorfman conformado o seu primeiro exílio $^{9}$, a sua ida para os Estados Unidos com sua mãe em 1945, aos dois anos e meio de idade, ao encontro do pai e do marido, teria sido o início da constituição de sua identidade flutuante. A mudança para Nova Iorque, em uma idade tão tenra, iria produzir o bilinguismo de Ariel, não apenas em termos linguísticos, mas também, e principalmente, nos marcos culturais pelos quais ele foi indelevelmente assinalado.

Apenas para mencionar um exemplo da importância da experiência norte-americana no início da vida de Ariel, ele lembra, nas suas memórias, de ter sido internado com pneumonia em um hospital, onde esteve por três semanas, recebendo a visita dos pais, que não ficaram com ele e que não puderam lhe falar. Quando está para sair do hospital, encontrando os pais e sendo por eles interpelado na língua materna, Dorfman, segundo sua mãe, teria dito: “I don’t understand”. E o menino não falou “(...) sequer uma palavra em espanhol durante dez anos” (DORFMAN, 1998, p. 45). E inventou um nome para si nesta estada. Quis ser Edward; Ed ou Eddie, para os amigos.

Com o avanço da “Guerra Fria” nos Estados Unidos e das perseguições políticas acarretadas por ela, o pai de Ariel, que cumpria função diplomática naquele país, precisou, novamente, fazer as malas. Em meados da década de cinquenta, a família se muda para o Chile. Em Santiago, Ariel terá ocasião de fazer suas escolhas. A escolha que seu pai fizera em 1954 tornou-se a sua também nos anos a seguir. Em 1960, ele ingressa na faculdade e logo (1961) conhece Angélica, a chilena com a qual casaria cinco anos depois. Em 1967, nasce o primeiro filho do casal, Rodrigo. Nestes anos de 1960, teve a oportunidade de refazer os laços com uma latino-americanidade que, a rigor, ele não havia conhecido. $\mathrm{O}$ contraste proporcionado pela experiência nos Estados Unidos vai se delineando cada vez com maior clareza para Ariel, no seu percurso chileno. Neste sentido, creio que (1) a escolha do pai pelo

\footnotetext{
9 “Talvez tenha sido o meu primeiro exílio: não pedi para nascer, não escolhi nada, nem meu rosto, nem o rosto de meus pais, nem essa extrema sensibilidade que sempre exsuda de mim, nem a erupção prematura em minha pele, nem a minha remota asma, nem o meu país vizinho, nem o meu nome impronunciável” (DORFMAN, 1998, p. 24).
} 
Chile, (2) a formação universitária de Ariel naquele país, (3) o encontro definitivo com uma mulher chilena e (4) o nascimento do primeiro filho, chileno, representam quatro âncoras a firmar esta identidade. “(...) parei de dizer que era da Argentina, comecei a mentir para os outros e para mim mesmo, respondendo que era chileno” (DORFMAN, 1998, p. 212).

Mas não nos enganemos. O eixo do livro é sempre o mesmo. Ele fala sobre ser fraturado e sobre ser inteiro (POSTEL, 1998). Dirigindo-se para o Sul, olhando para o Norte. Caminhos retilíneos não combinam com esta equação. Dorfman “(...) era irremediavelmente duplo” (DORFMAN, 1998, p. 284). Em 1968, ele vai para Berkeley (EUA) com a família, e lá permanece até 1970. Com esta viagem, garantida por uma bolsa de estudos, ele queria resolver problemas financeiros, mas também culturais.

Ele retornaria em 1970 ao Chile para participar dos três anos da experiência socialista de Allende no governo. A sensação descrita pelo autor em suas memórias era de estar vivendo uma comunhão afetiva única com o país que ele elegeu para sua pátria. Nas suas palavras: “Tudo era novo e pedia para ser escrito, e eu partilhava uma língua gloriosa com as pessoas que estavam escrevendo o texto da realidade e eu queria pôr cada palavra no papel” (DORFMAN, 1998, p. 316). O dia 11 de setembro de 1973 produziu outras mãos para dar forma à realidade. A mão firme e grossa de um soldado que se fez presidente ${ }^{10}$ e que levou ao exílio os allendistas que foram poupados de exílios internos, quem sabe, mais duros.

A revolução estava sendo feita e Dorfman queria escrever, partilhar a língua, escrever “o texto da realidade”. Alguns anos antes, em 1964, na sua militância estudantil (e juvenil) pela libertação do povo, pelo esclarecimento dos pobres, ele mesmo deu-se conta de que estava “(...) mais apaixonado pelo conceito de el pueblo do que pelo povo de verdade” (DORFMAN 1998, p. 212). Em um dos momentos dramáticos daquele trágico setembro de 1973 - e que na sua memória vem sempre como um "tempo de descoberta da morte" - , quando titubeava em se abrigar na embaixada da Argentina e pensava em ficar, foi ao encontro de um contato, que lhe pergunta: “Acha realmente que é necessário aqui?” E ele responde que sim. Abel, o homem com o qual Ariel foi se aconselhar, diz: “Não. (...) É você que precisa ficar aqui. É você que precisa ficar para escrever o grande romance da Revolução Chilena. É por isso que quer ficar, não é?” (DORFMAN, 1998, p. 193). Dorfman era um intelectual, “(...) um homem que escreve, alguém que oferece palavras e histórias aos outros” (DORFMAN, 1998, p. 191). Seria também a vaidade pessoal que o prendia ao Chile?

\footnotetext{
${ }^{10}$ Aqui, faço alusão à descrição da mão do General Augusto Pinochet, conforme vista pelas jornalistas Raquel Correa e Elizabeth Subercaseaux, as quais realizaram uma longa entrevista com o presidente no final de seu governo, em 1989. Dizem elas: “Una mano grande, gruesa, firme. De soldado" (CORREA \& SUBERCASEAUX, 1989, p. 97).
} 
Jonathan Rollins, em avaliação recente baseada em uma entrevista concedida por Dorfman ao autor em 2008, lança a hipótese de que, em certas circunstâncias, a escrita constrói um parentesco com o lar; a narrativa como lar, como sua alternativa (ROLLINS, 2009). Neste sentido, um lar não é um lugar, mas locações. Teria Dorfman encontrado um lar na escrita? O Vladimiro que um dia se quis Edward e que depois adotou publicamente o nome do meio, Ariel, fez oscilar a sua identidade também no designativo pelo qual gostaria de ficar conhecido. O nome do meio, mais um interstício, feito centro.

Permitam-me concluir esta exposição com as palavras de Ariel Dorfman. As palavras que este intelectual gostaria de dizer ao jovem que ele foi um dia e que deixou o Chile em 1973 para se tornar hoje um expatriado. Estas palavras não deixam de ser um balanço que se pode fazer pela simples razão de que o tempo foi povoado pela experiência dos anos, que o presente faz nascer. Diz ele de seu outro eu:

Com o passar dos anos, eu botaria, relutantemente, cuidadosamente, contra a parede aquele jovem e aqueles três anos que ele viveu, eu o transformaria, lentamente, no homem que escreve estas palavras, eu lhe contaria o que tinha aprendido com essa derrota, como fui um daqueles que, inadvertidamente, contribuiu para a formação daquele buraco negro naquela sacada [do Palácio de La Moneda]. Eu lhe diria que não deveria ter confiado no Estado para solucionar todos os problemas do Chile ou na revolução para resolver todos os problemas. Eu lhe diria que foi injusto sobrecarregar todo um povo com a sua salvação. Eu the diria que o desejo de pureza pode levar ao fanatismo, à rivalidade étnica e ao fundamentalismo. Eu lhe diria que os pobres não precisam ser representados por uma voz paternalista, por mais benevolente que seja. Eu lhe diria que se você reduz tudo a política e ideologia, acaba totalizando, tirando o mistério da vida e explicando com excessiva facilidade o que, às vezes, não tem explicação, acaba não deixando espaço para as suas próprias imperfeições. Eu lhe diria que não devia ter ignorado as violações dos direitos humanos nos países socialistas por insensibilidade e conveniência política. Eu lhe diria como as mulheres foram postergadas na revolução e como nem mesmo imaginávamos que a nossa atitude em relação à natureza a pilhava e poluía.

Eu lhe diria isso e muito mais a partir do retrospecto do futuro, tudo que eu achava que ele tinha feito de errado.

Mas há uma coisa que eu não lhe diria, àquele jovem que eu era. Não lhe diria, nunca disse ao meu alter ego no passado: que ele errou ao se rebelar (DORFMAN, 1998, p. 333-4).

Esta é uma autocrítica pessoal e, ao mesmo tempo, geracional de Ariel Dorfman. Mas é também um acerto de contas que revela um homem em paz com o seu passado.

Com certeza, a explicação para a mobilidade espacial dos avós de Dorfman no início do século $\mathrm{XX}$ responde a demandas que não podem ser feitas equivalentes àquela que deslocou seus pais já em meados do novecentos. Da mesma forma, a emigração de Ariel 
Dorfman e sua família para os Estados Unidos nos anos 1970 atende a necessidades não homólogas a de seus pais quando estes foram para aquele país alguns anos antes. Por outro lado, as razões da diáspora trazidas pelas memórias do autor não podem ser universalizadas a outras famílias e grupos sociais nas mesmas conjunturas citadas.

No caso específico de Ariel, é bem sabido que o Governo de Augusto Pinochet, pelas condições adversas impostas aos opositores da ditadura, multiplicou e diversificou as situações de saída do Chile. Entre os que deixaram o país ao longo desse governo, talvez um milhão de pessoas, Dorfman pertence ao grupo majoritário daqueles com uma boa condição social e intelectual, embora ele não tenha ido para o destino mais procurado - pelo menos até 1976 -, e que era seu país de nascimento, a Argentina. Desse montante total, Dorfman integrou o quinto que ao final da ditadura não retornou em definitivo ao Chile. Se muitos dos que deixaram o Chile para diferentes países da Europa e para os Estados Unidos sofreram as dificuldades de adaptação próprias ao (des)encontro de culturas e línguas diversas, este destino, pelas razões aqui já elencadas, não alcançou a Ariel ${ }^{11}$. Neste caso, a escolha pregressa de seus pais, quando ele era criança, acabou por orientar a sua própria decisão.

A história de vida de Ariel Dorfman e sua múltipla trajetória espacial desde tenra idade ajudam a compor um quadro no qual o melhor caminho talvez seja “(...) abandonar a falsa alternativa entre ‘desterritorialização’ e ‘reterritorialização’” (JEANPIERRE, 2008, p. 194). Aludindo às perseguições havidas nos anos 1970, Laurent Jeanpierre afirma que "Pela primeira vez, o exílio foi reconhecido, simultaneamente, como dano moral e, sobretudo, como ato político, não mais representando uma traição em relação àqueles que resistiram sem deixar seus países” (JEANPIERRE, 2008, p. 198), embora este conceito ainda hoje seja objeto de controvérsia. Ariel Dorfman parece ter resolvido satisfatoriamente, do ponto de vista literário, dois mitos com os quais ele foi levado a lidar nas últimas décadas e que constantemente o interpelaram. Nas suas palavras: “o mito que me prometeu que eu retornaria para sempre [e] o mito que murmurou que eu vagaria para sempre” (DORFMAN, 1998, p. 354). A prosaica verdade de uma vida não cabe em absolutos, tampouco em absolutos inconciliáveis.

\footnotetext{
${ }^{11}$ Para um detalhamento desses e de outros dados referentes à diáspora chilena durante o governo de Pinochet, ver o texto de SZNAJDER; RONIGER, 2007.
} 


\title{
WORDS THAT FIT A LIFE TRAJECTORY: memoirs of Ariel Dorfman
}

\begin{abstract}
This paper analyzes the book Heading South, Looking North (1998), written by the American intellectual Ariel Dorfman. Considering the reading of his memoirs, it attempts to understand how the author, based on his life as well as his family's, has constructed the bilingualism that has characterized his trajectory. Through the constitution of his multiple, but not always excluding identities, Dorfman has pointed out reasons for the approximation between a man linked to left-wing projects in Latin America and North-American cultural references, by means of migrations that have always been present in his life.
\end{abstract}

Keywords: “Heading south, looking north”. Chile. United States. Migrations.

\section{Referências}

ALVES, F. A. N. A morte e a donzela e Que bom te ter viva: o teor testemunhal. Literatura em Debate, Frederico Westphalen: URI, v. 4, n. 6, p. 105-120, ago 2010.

COMPARATO, B. K. A anistia entre a memória e a reconciliação: dilemas de uma transição política ainda inconclusa. XIV Congresso Brasileiro de Sociologia. Rio de Janeiro, 28 a 31 de julho de 2009. Disponível em: <http://www.escoladegoverno.org.br/biblioteca/236>.

CORREA, R. \& SUBERCASEAUX, E. Ego sum Pinochet. Santiago: Zig.Zag, 1989.

DORFMAN, A. A morte e a donzela. Rio de Janeiro: Paz \& Terra, 1992.

DORFMAN, A. Uma vida em trânsito. Memórias de um homem entre duas culturas. Rio de Janeiro: Objetiva, 1998.

DORFMAN, A. O longo adeus a Pinochet. São Paulo: Companhia das Letras, 2003.

JEANPIERRE, L. O lugar da exterritorialidade. In: RODRIGUES, H.; KOHLER, H. (Orgs.). Travessias e cruzamentos culturais. A mobilidade em questão. Rio de Janeiro: FGV, 2008, p. 183-202.

MC CLENNEN, S. A. Interview with Ariel Dorfman. Context, 15, University of Illinois, Urbana-Champaign, Dalkey Archive Press, s/d. Disponível em:

$<$ http://www.dalkeyarchive.com/article/show/216>.

POSTEL, D. Ariel Dorfman Interview. The Progressive, Madison, December 1998.

Disponível em: <http://www.progressive.org/mag_intv_dorfman>. 
ROLLINS, J. Ariel Dorfman writes home: literary citizenship and transnational belonging. In: RAHIMY, T. (ed.). Representation, expression and identity: interdisciplinary insights on multiculturalism, conflict and belonging. Oxford: Interdisciplinary Press, 2009, p. 69-78.

SZNAJDER, M. \& RONIGER, L. Exile communities and their differential institutional dynamics: a comparative analysis of the chilean and uruguayan political diasporas. Revista de Ciencia Política, Santiago: PUC de Chile, vol. 27, n. 1, p. 43-66, 2007. 